\title{
ВMJ Global Health Investing in non-communicable disease risk factor control among adolescents worldwide: a modelling study
}

To cite: Watkins D, Hale J, Hutchinson B, et al. Investing in non-communicable disease risk factor control among adolescents worldwide: a modelling study. BMJ Glob Health 2019:4:e001335. doi:10.1136/ bmjgh-2018-001335

Handling editor Seye Abimbola

Received 29 November 2018 Revised 12 February 2019 Accepted 15 February 2019

\section{Check for updates}

(c) Author(s) (or their employer(s)) 2019. Re-use permitted under CC BY-NC. No commercial re-use. See rights and permissions. Published by BMJ.

${ }^{1}$ Division of General Internal Medicine, University of Washington, Seattle, Washington, USA

${ }^{2} J o h n s$ Hopkins University Bloomberg School of Public Health, Baltimore, Maryland USA

${ }^{3}$ RTI International, Seattle, Washington, USA

${ }^{4}$ RTI International, New Delhi, India

${ }^{5}$ School of Public Health, MRCPHE Centre for Environment and Health, Imperial College London, London, UK

Correspondence to

Dr David Watkins

davidaw@uw.edu

\section{ABSTRACT}

Introduction Exposure to non-communicable disease (NCD) risk factors is increasing among adolescents in most countries due to demographic, economic and epidemiological forces. We sought to analyse the potential health impact and costs of implementing NCD risk reduction interventions among adolescents worldwide. Methods We identified six interventions targeted at adolescent tobacco smoking, heavy episodic drinking and obesity and supported by effectiveness and costeffectiveness evidence. Based on a population-level cohort of adolescents in 70 representative countries, we assessed the global mortality consequences of fully implementing these interventions over 2020-2070 using the potential impact fraction approach. We calculated the economic benefits of reduced mortality and estimated the required financial costs, discounting both at $3 \%$ annually. We also conducted best-case and worst-case scenario analyses. Results Full implementation of these interventions worldwide could avert nearly $10 \%$ of premature deaths among this cohort, translating to about US $\$ 400$ billion in cumulative economic benefits. Cumulatively, the required costs would be about US $\$ 85$ billion, suggesting that every US $\$ 1$ of public money invested would generate US\$5 in increased human capital. Tobacco taxes generally conferred the highest economic returns; however, an indepth analysis of three countries illustrated the potential for different priorities, such as alcohol control, to emerge. Conclusion From a life course perspective, implementation of a package of interventions to reduce NCD risk among adolescents worldwide would substantially reduce premature mortality at reasonable costs. Our analysis illustrates the importance of integrating NCD prevention policies into the emerging global agenda for adolescent health and well-being.

\section{INTRODUCTION}

The combined effects of demographic shifts, globalisation and economic growth have generated an environment in which more children and adolescents are exposed to risk factors for non-communicable diseases (NCDs) than ever before in history. ${ }^{1-3}$ Left unchecked, these risk factors-which include but are not limited to tobacco and

\section{Key questions}

What is already known?

- Major non-communicable disease (NCD) risk factors, such as tobacco smoking, harmful alcohol use and obesity, are increasing worldwide, including among adolescents.

- A number of population-level economic analyses have been conducted on NCD risk reduction, but these have largely focused on adults.

\section{What are the new findings?}

- We identified six evidence-based interventions that could reduce NCD risk factor levels and premature mortality among today's adolescents by $10 \%$ over the next 50 years.

- Relative to the package's costs, its health impact among adolescents justifies action-even without considering the health impact in the broader population (eg, among adults).

- Scale-up of tobacco and alcohol control policies to WHO-recommended implementation levels would achieve impressive health gains at modest costs to government; obesity interventions, while effective, would generate less health per dollar spent.

What do the new findings imply?

- From a 'life course' perspective, a multipronged approach to tackling NCD risk among adolescents could produce a high potential return on investment particularly in the areas of tobacco and harmful alcohol use.

- In light of the concerning worldwide trends in child and adolescent body mass index, more evidence is urgently needed on approaches to reducing obesity that are scalable and cost-effective in low-income and middle-income country settings.

- Policies such as the ones analysed here could feature more prominently on the global adolescent health and development agenda; our analysis also provides a new lens through which to view the growing problem of global NCDs.

alcohol use, diets high in highly processed foods and reduced physical activitythreaten to cut short the life expectancy of current adolescents by many years due to a 
rise in cardiovascular diseases, cancers, mental disorders, respiratory disorders and injuries during middle age. ${ }^{4}$ Although considerable progress has been made on reducing smoking in a number of countries, it has not been sufficient in many countries, and regions such as Africa and the Eastern Mediterranean will continue to experience a rise in the number of smokers if current trends continue. ${ }^{5}$ Apart from tobacco use, other NCD risk factors have persisted (or increased), largely unabated; the most concerning of all is a massive uptick in obesity among young people. ${ }^{6}$

Much of the recent discourse on NCDs has focused on scaling up evidence-based clinical, public health and 'intersectoral' interventions or packages of interventions. ${ }^{7}$ Economic assessments of NCD risk factor policies have been conducted by the WHO and as part of Disease Control Priorities, Third Edition (DCP3), among others. ${ }^{89}$ Yet, the NCD agenda has largely advocated for policy change on the grounds that it will produce health gains among adults today and in the near future. Adolescents have rarely been mentioned as a potential target or beneficiary population for such interventions. At the same time, the global adolescent health and well-being agenda has largely (and for good epidemiological reasons) focused on communicable disease prevention and control, and more recently, mental health and injury prevention. ${ }^{10}$

There are at least two compelling reasons to link the NCD prevention and adolescent health agendas. The first reason is that the adolescent period is, from a neurodevelopmental perspective, an ideal opportunity to intervene to instil positive behaviours and healthy lifestyles that will carry on into adulthood. (The other side of this issue is that adolescents are especially susceptible to peer pressure to acquire unhealthy habits. $)^{11}$ The second reason is that there is increasing momentum for raising the profile of adolescents on the global health and development agenda, providing an opportunity to reframe NCDs from a life course perspective. $^{10}$

Given the desperate need for the NCD agenda to connect better with decision-makers and health advocates, it seems worthwhile to explore the costs and consequences of acting on NCDs from the perspective of young people. In this paper, we conduct an 'investment case', including an assessment of intervention costs and health benefits, for reducing NCD risk exposure among adolescents around the world. We focus on three major NCD risk factors: tobacco use, alcohol use and obesity. We model the potential worldwide health and economic gains from a package of six interventions and estimate the financial costs required for governments to implement these interventions at scale.

\section{METHODS}

Our analysis involved four major steps, summarised below. The online supplementary appendix provides greater detail on data sources and methods used. In brief, we generated baseline demographic data and risk factor prevalence levels for a global cohort of individuals aged 5-14 in the year 2015, that is, individuals who will be adolescents (defined in this study as ages 10-19) in the year 2020. We then identified a package of interventions using structured literature reviews and gathered information on intervention effectiveness and costs. Next, we calculated the population-level health impact of these interventions over the next five decades. A time horizon of 50 years 2020-2070 was chosen so that the cohort age range (see below) would be 10-19 at the start of the analysis and 60-69 at the end of the analysis, so the deaths averted during the analysis time frame would be considered 'premature' deaths (aligned with the Sustainable Development Goal (SDG) 3 NCD target). We then estimated the value of these health improvements in monetary terms and the public cost of scaling up the interventions alone and in combination.

\section{Baseline cohort data}

We identified a list of 70 countries (online appendix table A1) that would be representative of the global and (World Bank) country income group environment in terms of demography ( $86 \%$ of the global population in 2015), epidemiology, costs and current level of intervention implementation. These countries were largely chosen to align with the WHO's 2017 health SDG price tag report, ${ }^{12}$ though we added Germany, Japan, Russia and the USA to this list to ensure that high-income settings were represented in this analysis. We extracted age-specific population estimates for each of these countries, representing a cohort of adolescents and preadolescents. ${ }^{13}$ We obtained data on three risk factor measures in adolescence: prevalence of daily smoking, prevalence of heavy episodic drinking and mean body mass index (BMI). ${ }^{14} 15$

In this study, we report results for three types of geographies: by country, by World Bank income group (in which each of the 70 countries was assigned to one of the four income classifications, then results for countries in each group were aggregated) and 'global', in which we extrapolated world population totals from the aggregate results of all 70 countries. The latter case presents results as if the 70 countries are representative of worldwide trends.

\section{Identification of interventions}

We drew on global policy reports, prior systematic reviews and the $D C P 3$ publications to select interventions against NCD risk factors that were likely to provide good value for money and have specific evidence supporting their effectiveness among adolescents (online appendix pp. 4-5). Our final list contained six interventions, two directed at each of the three risk factors (table 1). Three of our six interventions were excise taxes (on tobacco, alcohol and sugar-sweetened 
Table 1 Adolescent non-communicable disease risk factor interventions and assumptions

\begin{tabular}{|c|c|c|c|}
\hline Risk factor & Intervention & Effectiveness estimate (source) & Outcome \\
\hline $\begin{array}{l}\text { Tobacco } \\
\text { smoking }\end{array}$ & $\begin{array}{l}\text { Increase in excise tax to } 75 \% \text { of final } \\
\text { retail price of tobacco products } \\
\text { Point-of-sale advertising bans }\end{array}$ & $\begin{array}{l}\text { For every } 10 \% \text { increase in price, smoking } \\
\text { prevalence declines by } 5.6 \% .^{31} \\
\text { Full implementation leads to a } 27 \% \\
\text { reduction in the chance of smoking. }\end{array}$ & $\begin{array}{l}\text { Reduction in monthly } \\
\text { smoking prevalence } \\
\text { among adolescents }\end{array}$ \\
\hline $\begin{array}{l}\text { Heavy episodic } \\
\text { drinking }\end{array}$ & $\begin{array}{l}\text { Compared with current levels, } 50 \% \\
\text { increase in excise tax } \\
\text { Complete ban on alcohol advertising } \\
\text { (television, radio, outdoors and print) }\end{array}$ & $\begin{array}{l}\text { For every } 10 \% \text { increase in price, heavy } \\
\text { episodic drinking declines by } 7.3 \% .{ }^{33} \\
\text { Full implementation leads to a } 42 \% \\
\text { reduction in heavy episodic drinking. }\end{array}$ & $\begin{array}{l}\text { Reduction in heavy } \\
\text { episodic drinking among } \\
\text { adolescents }\end{array}$ \\
\hline $\begin{array}{l}\text { High body } \\
\text { mass index }\end{array}$ & $\begin{array}{l}\text { Addition of a } 20 \% \text { excise tax on } \\
\text { sugar-sweetened beverages } \\
\text { School-based physical activity and } \\
\text { nutrition programmes }\end{array}$ & $\begin{array}{l}\text { For every } 10 \% \text { increase in price, } \\
\text { consumption declines by } 10 \% .^{35} \\
\text { Full implementation leads to a long term } \\
0.29 \mathrm{~kg} / \mathrm{m}^{2} \text { reduction in body mass index } \\
\text { among participants. }{ }^{22}\end{array}$ & $\begin{array}{l}\text { Reduction in population } \\
\text { mean body mass index } \\
\text { among adolescents }\end{array}$ \\
\hline
\end{tabular}

beverages); two were bans on advertising (of tobacco and alcohol) and one was a school-based intervention to promote physical activity and healthy diet. ${ }^{16}$

We looked through a number of data sources to identify the range of plausible intervention effect sizes from reducing the three risk factor measures. We gave priority to estimates for low-income and middle-income country settings and only used adolescent-specific effectiveness data. Importantly, we were interested in the impact of scaling up each intervention from its current level of implementation in each country to 'full implementation', defined as scale-up of the intensity of the intervention to target levels (eg, increase in tobacco excise taxes to $75 \%$ of final retail price per WHO recommendations) and/or to ensure exposure of $100 \%$ of the target population (eg, all school-going adolescents receive the physical activity and nutrition education intervention). Data on baseline levels of implementation were taken from the WHO NCD progress monitor report in 2017 and from the WHO tobacco country profile. ${ }^{17} 18$

\section{Estimation of health consequences}

In order to estimate the potential long-term mortality reduction from our interventions, we constructed survival curves for 2020-2070 for each country, two 5-year age groups (current adolescents aged 10-14 years and 15-19 yearss) and both sexes. These curves were developed from the World Population Prospects 2017 projections of all-cause mortality by age, sex and country for each 5-year period during our analysis time horizon (online appendix pp.7-8). These projections can be regarded as a 'business-as-usual' scenario where no additional scale-up of the interventions would occur.

We then estimated changes in cause-specific death rates due to the long-term shift in each of the three risk factor outcomes from the business-as-usual scenario to the intervention scenarios. We used estimates of death rates by age, sex, country and cause of death from the WHO for the year $2016 .{ }^{19}$ We assumed that absolute rates for specific causes of death would remain unchanged from 2016 levels in the future in the absence of any additional intervention. We then calculated population-attributable fractions for each cause-risk factor pair and used the shift in risk factor exposure to calculate counterfactual population-attributable fractions, per cent reduction in mortality by cause and then absolute reductions in attributable mortality rates for each intervention. ${ }^{6}{ }^{20}$ Absolute reductions in mortality rates were subtracted from the aforementioned projected all-cause mortality rates to estimate changes in mortality, life-years gained and deaths averted over 2020-2070.

\section{Analysis of costs and economic benefits}

We valued the life years gained during 2020-2070 in monetary terms using the human capital approach in which a life year gained is valued at current gross domestic product (GDP) per capita for a given country.

We used the WHO NCD Costing Tool to estimate the financial costs of scaling up and sustaining the five population-level policies (taxes and advertising bans). ${ }^{21}$ We estimated the cost of the school-based programme using unit cost data from the programme itself as implemented in China and methods for extrapolating these costs to other countries. ${ }^{22}{ }^{23}$ Importantly, while we modelled health benefits from 2020 to 2070 (because NCD-related mortality only starts to rise appreciably above age 20), we modelled costs from 2015 to 2024 for the school-based programme-to capture the cost of implementing the school programme intervention among current adolescents - and from 2015 to 2070 for the policy measures in order to account for the policy remaining in place throughout individuals' life course. Both economic benefits and costs were discounted at $3 \%$ per year.

\section{Other analyses}

We accounted for uncertainty in our model input parameters by conducting two scenario analyses (best 


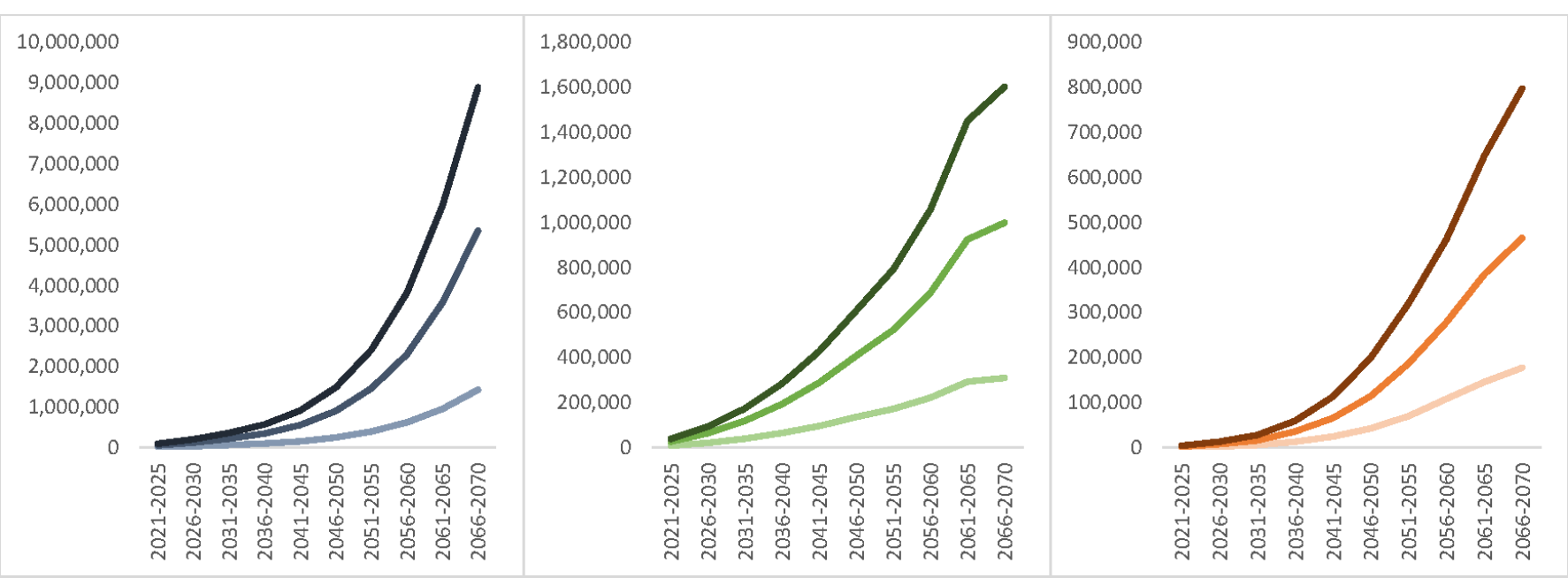

Figure 1 Evolution of health benefits from interventions, 2020-2070. The two interventions for each risk factor were modelled both together and separately, and the 'combined' impact was used in this figure. Left panel: tobacco smoking; middle panel: heavy episodic drinking; right panel: high body mass index. The y-axes show 'global' deaths averted during every 5-year interval; numbers are based on extrapolation of 70 country results to global population totals. Upper and lower traces in each panel refer to the best-case and worst-case scenario analyses; the middle trace refers to the base-case scenario (see text for details).

case and worst case) in addition to the base-case scenario (online appendix p. 6; appendix table A3). Plausible low and high values of model parameters were identified, and in the scenario analyses the relevant most-extreme value of each parameter was used.

The funder of the study had no role in study design, data collection, data analysis, data interpretation or writing of the report. The corresponding author had full access to all the data in the study and had final responsibility to submit for publication. This study was not considered human subjects research and thus did not require ethics committee approval.

\section{RESULTS}

\section{Health impact}

In the 70 countries included in this analysis, there were an estimated 1.1 billion individuals aged 5-14 years in 2015. In the business-as-usual scenario informed by United Nations population projections, $19 \%$ of these current youth would die by the year 2070 , that is, there would be 210 million premature deaths from all causes Full implementation of the package of six interventions would avert 21 million of those premature deaths over the next 50 years (9.8\% of deaths from all causes), including 15 million deaths attributable to smoking, 4.2 million deaths attributable to alcohol use and 1.6 million deaths attributable to high BMI. Improvements in health outcomes would increase with each decade as the cohort passes through middle age (figure 1).

The table 2 presents disaggregated estimates of premature deaths averted. The vast majority of deaths averted would be in countries that were classified in 2017 as middle income (together comprising the vast majority of the world's population). The variation in the magnitude of health effects by risk factor would be similar across income groups, with tobacco-attributable deaths averted conferring the greatest share and obesity-attributable deaths conferring the least share of total health benefits.

In the cases of tobacco and alcohol, advertising bans would be somewhat less effective than the modelled

Table 2 Health consequences of adolescent non-communicable disease risk factor reduction over 2020-2070

\begin{tabular}{lllll}
\hline & \multicolumn{4}{l}{$\mathbf{5 0}$ Incomear cumulative health benefits (millions of premature deaths averted) } \\
\cline { 2 - 5 } Iobacco use & Alcohol use & High body mass index & All risk factors \\
\hline Low-income countries & $1.5(0.69$ to 2.1$)$ & $0.46(0.14$ to 0.69$)$ & $0.10(0.038$ to 0.17$)$ & $2.0(0.86$ to 3.0$)$ \\
Lower-middle-income countries & $8.3(2.2$ to 14$)$ & $2.8(1.0$ to 3.9$)$ & $0.86(0.33$ to 1.4$)$ & $12(3.5$ to 19$)$ \\
Upper-middle-income countries & $4.3(0.95$ to 7.5$)$ & $0.72(0.12$ to 1.6$)$ & $0.53(0.20$ to 0.93$)$ & $5.6(1.3$ to 10$)$ \\
High-income countries & $0.82(0.25$ to 1.3$)$ & $0.24(0.078$ to 0.34$)$ & $0.075(0.028$ to 0.13$)$ & $1.1(0.35$ to 1.7$)$ \\
Global & $17(4.6$ to 28$)$ & $4.8(1.6$ to 7.4$)$ & $1.8(0.67$ to 3.0$)$ & $24(6.8$ to 39$)$ \\
\hline
\end{tabular}

Estimates of premature (under-70) deaths averted, that is, statistical lives saved, are not discounted. Range of values given in parentheses come from the worst-case and best-case scenario analyses. 'All risk factors' totals may not add up exactly due to rounding. 'Global' totals aggregate the totals from the four income groups divided by $88 \%$ (the percentage of the $5-14$ world population represented by the 70 countries). 
increases in taxes. In the case of obesity, the school-based intervention would confer the vast majority of the total health benefits.

\section{Economic benefits}

Using the human capital approach, the cumulative economic value of the package of six risk factor interventions was estimated at US $\$ 400$ billion (discounted) by the year 2070 , ranging from US $\$ 110$ billion in the best-case scenario to US $\$ 650$ billion in the worst-case scenario. In general, differences in benefits from each intervention/ risk factor and across income groups were similar in magnitude to the health impacts shown in table 2 (online appendix tables A9-A10 and appendix figure A4 provide more detailed estimates).

We found a remarkable variation in the range of economic benefits across countries and income groups. A factor of about five separated the highest and lowest countries in each income group, and roughly speaking, average benefits were proportional to GDP levels across income groups. The major factors that drove the variation in economic benefits across countries within each income group: (1) current NCD risk exposure patterns, (2) baseline mortality levels by age group and cause of death, (3) extent of policy implementation and baseline and (4) macroeconomic conditions (online appendix p. 9, appendix table A4).

\section{Implementation costs}

We estimated that the cumulative incremental financial cost of scaling up and sustaining this NCD risk factor package would be US $\$ 85$ billion globally or about US $\$ 1.7$ billion annually on average (table 3 ). By far, the schoolbased programme would have the highest cost (US $\$ 75$ billion). Most of this cost would be borne in the first few years, that is, while today's adolescents are still attending school. The other five interventions (all policy measures) would have more modest costs (on average about US\$2.0 billion per intervention), mostly for policy administration or enforcement.

\section{Return on investment}

Since we calculated the financial costs of these interventions to national governments and estimated the economic benefits of reduced mortality, we can compare these two quantities to give a rough estimate of the 'return on investment' from public dollars devoted to these interventions. From the government perspective, saving one tobacco-attributable death would cost US $\$ 260$, and every dollar invested would generate US\$70 in greater human capital. Saving one alcohol-attributable death would cost US $\$ 810$, and every dollar invested would generate US\$26 in greater human capital. Saving one obesity-attributable death would cost US $\$ 43000$, and every dollar invested would generate US $\$ 0.50$ in greater human capital. This is because the obesity interventions are not highly effective in reducing mortality. For the package overall, each government dollar invested would generate US\$5 in human capital benefits (ranging from US\$1.1 to US\$13). The overall return on investment from the package would vary widely across countries (online appendix figure A5).

Table 3 Cumulative incremental costs of adolescent non-communicable disease risk factor reduction interventions, 20152070

\begin{tabular}{|c|c|c|c|c|c|c|c|}
\hline $\begin{array}{l}\text { World } \\
\text { region (1) }\end{array}$ & $\begin{array}{l}\text { Increase } \\
\text { in tobacco } \\
\text { excise tax }\end{array}$ & $\begin{array}{l}\text { Ban tobacco } \\
\text { advertising }\end{array}$ & $\begin{array}{l}\text { Increase in } \\
\text { alcohol tax }\end{array}$ & $\begin{array}{l}\text { Ban alcohol } \\
\text { advertising }\end{array}$ & $\begin{array}{l}\text { Addition } \\
\text { of sugar- } \\
\text { sweetened } \\
\text { beverage tax }\end{array}$ & $\begin{array}{l}\text { School } \\
\text { programmes }\end{array}$ & Total costs \\
\hline $\begin{array}{l}\text { Lower } \\
\text { middle- } \\
\text { income } \\
\text { countries }\end{array}$ & $\begin{array}{l}460 \\
\text { (320 to } 640)\end{array}$ & $\begin{array}{l}600 \\
(400 \text { to } 800)\end{array}$ & $\begin{array}{l}430 \\
\text { (320 to } 350)\end{array}$ & $\begin{array}{l}510 \\
\text { (110 to } 600)\end{array}$ & $\begin{array}{l}480 \\
(320 \text { to } 640)\end{array}$ & $\begin{array}{l}13200 \\
(8900 \text { to } 18000)\end{array}$ & $\begin{array}{l}16000 \\
(10000 \text { to } 21000)\end{array}$ \\
\hline $\begin{array}{l}\text { Upper } \\
\text { middle- } \\
\text { income } \\
\text { countries }\end{array}$ & $\begin{array}{l}440 \\
\text { (310 to } 610)\end{array}$ & $\begin{array}{l}550 \\
\text { (370 to } 730)\end{array}$ & $\begin{array}{l}390 \\
\text { (70 to } 310)\end{array}$ & $\begin{array}{l}250 \\
\text { (30 to 250) }\end{array}$ & $\begin{array}{l}460 \\
(310 \text { to } 610)\end{array}$ & $\begin{array}{l}25000 \\
(17000 \text { to } 33000)\end{array}$ & $\begin{array}{l}27000 \\
(18000 \text { to } 35000)\end{array}$ \\
\hline
\end{tabular}

Costs are in millions of 2016 US dollars, discounted at $3 \%$ annually. The range of values given in parentheses come from the bestcase and worst-case scenario analyses. 'Total costs' may not add up exactly due to rounding. 'Global' totals aggregate the totals from the four income groups divided by $88 \%$ (the percentage of the 5-14 world population represented by the 70 countries). Worst case 'increase in alcohol tax' costs are lower than the base case because in this scenario many countries have fully achieved alcohol tax rate goals, meaning there are no additional costs to implement the policy (as well as no health benefits). 


\section{DISCUSSION}

In this analysis, we assessed the health consequences and potential costs of intensifying efforts to reduce three major NCD risk factors- tobacco use, alcohol use and obesity-among today's adolescents worldwide. A package of six interventions, all of which are preventive and would be implemented by sectors other than the health sector, would prove highly effective at reducing global mortality at modest levels of investment, with the most attractive returns being in the areas of tobacco and alcohol use reduction. Despite considerable uncertainty in the underlying data sources, our analysis points to the high returns from early intervention on NCD risk. Our study adds novel evidence to the small literature on NCD risk among children and adolescents in low-income and middle-income countries.

Dollar for dollar, and in terms of total population benefits, tobacco control remains one of the single most attractive interventions in public health. Yet, many barriers to full implementation of the WHO's 'MPOWER' package remain. ${ }^{17}$ Advocates and civil society organisations should step up their efforts on tobacco control, which this analysis suggests will be highly worthwhile-even if only the future impact on today's adolescents is considered.

Papers prepared for the Copenhagen Consensus estimated the benefit-cost ratio for tobacco taxation among current adults to be $40-52 .{ }^{24}$ We anticipate that the benefits of reducing smoking in adolescence would exceed that for adults as the adolescents will gain more years of healthy life. Our analysis points to impressive benefits from reducing tobacco use among younger-aged populations, which accumulate large health improvements over decades.

Our findings are broadly consistent with a recent global-level cost-effectiveness analysis of WHO-recommended alcohol policies. ${ }^{25}$ However, relative to the total disease burden attributable to alcohol, the gains from our alcohol interventions would be relatively modest. This is probably because we focused only on heavy episodic drinking as an outcome. Although it is risky for those who do it, only a small fraction of adolescents engage in heavy episodic drinking frequently enough to cause serious health damage. Reducing chronic daily alcohol use would have additional health benefits not captured in our analysis. ${ }^{3}$ Still, effects of policies on chronic daily alcohol overconsumption are more challenging to quantify, and this pattern of use is much more common among adults than among adolescents.

Obesity reduction remains a challenging issue worldwide. We found that, relative to implementation costs, the health impacts were much lower for the two obesity interventions compared with the tobacco and alcohol interventions. Although sugar-sweetened beverage taxes have modest health benefits in isolation, ${ }^{26}$ their costs are low, and they can pave the way for more aggressive fiscal policies on more significant, upstream dietary targets (like sugar). ${ }^{27}$ Some evidence suggests that these taxes may have a 'signalling' effect to consumers to reduce consumption in a manner that is additive to the reduction in consumption due to price increases. ${ }^{28}$

While school-based interventions are quite effective, they are inherently expensive because they are labour intensive when compared with taxes and regulations. The programme model we analysed in this paper was developed in China; adaptation, experimentation and monitoring would be needed in other countries to keep down costs and ensure that programmes produce longlasting behaviour change. Scores of published, effective programmes are now available as templates for designing local programmes ${ }^{29}$; however, most adolescent obesity research is still being conducted in high-income countries. More research is needed on scalable models of obesity-related behaviour change in diverse country settings. This research should include careful assessments of costs.

While our global-level report was conducted using data aggregated from 70 countries, the focus of the analysis was not on generating tailored estimates of costs and health consequences in each intervention in each country. However, for a separate analysis, we worked with local experts in India, Kenya and Indonesia to adapt this six-intervention package to their country contexts. Boxes 1 and 2 illustrate the variations that emerged when applying these recommendations at the local level. Other countries could use this package as a starting point for local analysis and development of a customised implementation plan.

Our findings suggest a series of concrete, early priorities for countries that currently have limited fiscal and implementation capabilities and other competing priorities such as infectious disease control. Large and rapid hikes in tobacco and alcohol tax rates are likely to be top priorities in all countries, and they will generate considerable new revenues for health and other development priorities. Analyses of the distributional impact of tobacco taxes have dispelled the notion-often advanced by the tobacco industry-that they adversely affect the poor. ${ }^{30} \mathrm{In}$ settings where sugar-sweetened beverage consumption is high-such as in Latin America and in some high-income countries-these taxes are likely to be earlier priorities. High-income and upper middle-income countries with high secondary school attendance rates may consider the educational programme. Most countries with limited resources and lower attendance rates will need to prioritise the other interventions in the short term to medium term.

Our analysis has several important limitations. We acknowledge that our intervention package was highly selective and had a high evidentiary standard; incorporation of additional, less well-evidenced interventions into this package of six interventions could lead to greater health gains, though the costs would also be higher than the costs presented in this analysis. We emphasise the significant level of uncertainty in our model parameters (online appendix table A3); we presented extreme best-case and worst-case scenarios for our findings to guide health planning in a transparent fashion. 
Box 1 Country-level translation of the adolescent noncommunicable disease (NCD) risk factor package: the case of India

Adolescents make up about $21 \%$ of India's population. ${ }^{36}$ Among adolescents aged $15-19$ years, $29 \%$ of boys and $4 \%$ of girls use tobacco and $11 \%$ of boys and $1 \%$ of adolescent girls consume alcohol. ${ }^{37}$ About $1.7 \%$ of adolescent boys and $2.4 \%$ of adolescent girls in India are overweight, and prediabetes is on the rise..$^{37}$ In recent years, India has made more progress on tobacco control policies relative to alcohol control, though a few states have implemented complete bans on alcohol. ${ }^{17}$

We obtained expert input from India-based youth public health experts to identify India-specific literature on these risk factors and adapt our analysis. Based on this review and consultation, we replaced a variety of model inputs for India and replaced the point-ofsale tobacco advertising ban with a school-based intervention called the 'Mobilizing Youth for Tobacco-Related Initiatives in India' (MYTRI) programme. ${ }^{38}$ We only evaluated alcohol taxes as alcohol advertising is already banned country wide. The online appendix explains these changes and provides detailed results.

In all, we estimated that the modified package of NCD interventions would avert about 3.5 million premature deaths among today's adolescents and would cost about US $\$ 415$ million annually (discounted) between 2015 and 2070 to implement, with the vast majority of those costs $(98 \%)$ due to running the school-based tobacco and obesity interventions during the years 2015-2024 (online appendix table $\mathrm{A} 11)$.

In contrast to the main messages from the global analysis, we found that the alcohol tax policy would generate higher gains relative to costs as compared with the tobacco tax, though both would provide a favourable return on investment. Similar to the global-level conclusions regarding the school-based obesity programme, we found that the value for money of the MYTRI programme was relatively low because of its higher costs (which arose from high labour costs).

We conclude that improvements in adolescent health and wellbeing in India could be best achieved by ramping up alcohol taxes. Continued escalation of tobacco taxes should also be a priority, however. Relative to these policies, school-based programmes to change NCD risk behaviours are expensive, sometimes conferring large benefits, but not at a rate that justifies the costs. Careful evaluation of programme costs and impact at scale (eg, at the state level) will be necessary to guide programme development in a balanced manner.

Further, we acknowledge the high level of uncertainty in how long-term costs might evolve. For example, longer life expectancy could lead to increased overall per capita consumption of healthcare, resulting in higher costs to government than estimated here. On the other hand, prevention of NCDs would result in lower healthcare costs on specific diseases, and especially in the case of expensive cardiovascular disease and cancer treatments, these cost savings might be substantial. These issues are discussed in greater detail in the online appendix (p. 10).

We did not estimate costs from a societal perspective as we could not account for all the indirect costs of implementing the selected interventions. This understates the full costs and means that the results appear more favourable than those from the Copenhagen Consensus. We
Box 2 Country-level translation of the adolescent noncommunicable disease (NCD) risk factor package: the cases of Kenya and Indonesia

Similar to the case study of India (Box 1), we reached out to local NCD experts in Kenya and Indonesia to adapt our global analysis to the context of these two countries. In both cases, NCD risk behaviours among adolescents are on the rise. ${ }^{14}$ Kenya also faces an ongoing double burden of malnutrition, and adolescents have access to minimally regulated, potent alcoholic brews. ${ }^{39}$ On the other hand, alcohol misuse is infrequent in Indonesia (for religious reasons), and the government has already fully implemented a range of alcohol control policies.

By contrast to the India case study, we struggled to identify local data that could be used to update our global results. The Appendix describes the few instances where we were able to use local literature and provides detailed results of the updated analysis; results are shown in online appendix table A11. (Alcohol interventions were excluded from the Indonesia analysis for the reasons described above.) Generally speaking, the package of tobacco, alcohol and obesity interventions in Kenya and tobacco and obesity interventions in Indonesia provided a reasonable return on investment (US\$6.8 and US\$29, respectively, gained for every government dollar invested) but the least attractive component of the package in both cases was the school-based obesity programme (US $\$ 0.10$ in Kenya and US $\$ 0.64$ in Indonesia generated for every dollar invested).

Since the analytic inputs for these two countries were similar to the global analysis, it is not surprising that the overall conclusions from these case studies were similar to the global-level findings. Lack of up-to-date, local data poses a major challenge to implementing NCD policies in these settings.

acknowledge the need for better data on healthcare costs and household consumption in low-income and middle-income countries, as well as multisectoral models of health interventions, both of which would allow for more rigorous assessments of intervention costs and benefits (online appendix pp. 2-3, p. 8).

Finally, one important limitation to highlight is that we employed the strong assumption that 'period' effects of risk factor reduction on attributable mortality rates will endure and are acceptable stand-ins for 'cohort' effects (online appendix p. 2). Analysing the latter over the next five decades would have required the development of highly complex models with unreasonable data requirements. In light of historical and ongoing successes in reducing NCD case fatality through healthcare interventions, we argue that the future burden of NCDs attributable to major risk factors-and hence the benefit of intervening on these risk factors-will increase over time. Costs may also decline over time as intervention implementation becomes more efficient.

\section{CONCLUSIONS}

This analysis provides a strong, quantitative justification for prioritising adolescent health and well-being within the global NCD agenda and for prioritising NCD prevention as a long-term development issue in the adolescent age 
group. We conclude that intervening now to reduce NCD risk among adolescents could significantly reduce premature mortality at reasonable costs. Country-level adaptation of this generic policy package will be required in order to ensure maximal uptake by decision-makers, sustainability of implementation and impact on population health.

Acknowledgements We would like to recognise Yu Wang, Samantha Horn and Nupoor Kulkarni, who assisted with literature review at various stages in this project. We would also like to acknowledge Professor Majid Ezzati, who assisted the authors in devising a method of measuring benefits across time and critically reviewed our preliminary analyses. We acknowledge the support of Plan International UK, who commissioned this work through a charitable grant made by the AstraZeneca Young Health Programme (YHP).

Contributors DW and RN conceived and designed the study and interpreted the data. JH and IK collected the data. DW, BH and VK analysed the data. DW wrote the first draft of the manuscript. All authors reviewed the draft and revised it for important intellectual content.

Competing interests None declared.

Patient consent for publication Not required.

Provenance and peer review Not commissioned; externally peer reviewed.

Open access This is an open access article distributed in accordance with the Creative Commons Attribution Non Commercial (CC BY-NC 4.0) license, which permits others to distribute, remix, adapt, build upon this work non-commercially, and license their derivative works on different terms, provided the original work is properly cited, appropriate credit is given, any changes made indicated, and the use is non-commercial. See: http://creativecommons.org/licenses/by-nc/4.0/.

\section{REFERENCES}

1. Afshin A, Reitsma MB, Murray CJL. Health effects of overweight and obesity in 195 countries. N Engl J Med 2017;377:1496-7.

2. $\mathrm{Ng} \mathrm{M}$, Freeman MK, Fleming TD, et al. Smoking prevalence and cigarette consumption in 187 countries, 1980-2012. JAMA 2014;311:183-92.

3. GBD 2016 Alcohol Collaborators. Alcohol use and burden for 195 countries and territories, 1990-2016: a systematic analysis for the global burden of Disease Study 2016. Lancet 2018;392:1015-35.

4. Olshansky SJ, Passaro DJ, Hershow RC, et al. A potential decline in life expectancy in the United States in the 21st century. $N$ Engl J Med 2005;352:1138-45.

5. Bilano V, Gilmour S, Moffiet T, et al. Global trends and projections for tobacco use, 1990-2025: an analysis of smoking indicators from the WHO comprehensive information systems for tobacco control. Lancet 2015;385:966-76.

6. Pearson-Stuttard J, Zhou B, Kontis V, et al. Worldwide burden of cancer attributable to diabetes and high body-mass index: a comparative risk assessment. Lancet Diabetes Endocrinol 2018;6:95-104.

7. WHO. Global action Plan for the prevention and control of noncommunicable diseases 2013-2020. Geneva: World Health Organization, 2013.

8. Bertram MY, Sweeny K, Lauer JA, et al. Investing in noncommunicable diseases: an estimation of the return on investment for prevention and treatment services. Lancet 2018;391:2071-8.

9. Watkins $\mathrm{D}$, Nugent $\mathrm{R}$, Saxenian $\mathrm{H}$, et al. Intersectoral policy priorities for health. 3rd edn. Washington: World Bank, 2018.

10. Sheehan P, Sweeny K, Rasmussen B, et al. Building the foundations for sustainable development: a case for global investment in the capabilities of adolescents. Lancet 2017;390:1792-806.

11. Hammond CJ, Mayes LC, Potenza MN. Neurobiology of adolescent substance use and addictive behaviors: treatment implications. Adolesc Med State Art Rev 2014;25:15-32.

12. Stenberg K, Hanssen O, Edejer TT-T, et al. Financing transformative health systems towards achievement of the health sustainable development goals: a model for projected resource needs in 67 low-income and middle-income countries. Lancet Glob Health 2017;5:e875-87.

13. UN. World population prospects: The 2017 revision. New York: United Nations Department of Economic and Social Affairs, Population Division, 2017.
14. NCD. Risk factor collaboration, 2018. Available: http://ncdrisc.org/ [Accessed 29 Aug 2018].

15. GBD 2016 Risk Factors Collaborators. Global, regional, and national comparative risk assessment of 84 behavioural, environmental and occupational, and metabolic risks or clusters of risks, 1990-2016: a systematic analysis for the global burden of Disease Study 2016. Lancet 2017;390:1345-422.

16. Li X-H, Lin S, Guo H, et al. Effectiveness of a school-based physical activity intervention on obesity in school children: a nonrandomized controlled trial. BMC Public Health 2014;14:1282.

17. WHO. Noncommunicable diseases progress monitor 2017. Geneva: World Health Organization, 2017.

18. WHO. Tobacco control country profiles. Tobacco free Initiative (TFI). Geneva: World Health Organization, 2017.

19. WHO. Global health estimates 2016: deaths by cause, age, sex by country and by region, 2000-2016. Geneva: World Health Organization, 2018.

20. Kontis V, Mathers CD, Rehm J, et al. Contribution of six risk factors to achieving the $25 \times 25$ non-communicable disease mortality reduction target: a modelling study. Lancet 2014;384:427-37.

21. WHO. Tools for implementing who Pen (package of essential noncommunicable disease interventions). Geneva: World Health Organization, 2018.

22. Meng L, Xu H, Liu A, et al. The costs and cost-effectiveness of a school-based comprehensive intervention study on childhood obesity in China. PLoS One 2013;8:e77971.

23. Watkins DA, Qi J, Horton SE. Costing UHC: the DCP3 model. In: DCP3 Working paper no 20: disease control priorities. 3rd edn, 2017.

24. Jha P, Nugent R, Verguet S, et al. Chapter 3. Chronic disease. In: Lomborg B, ed. Global problems, smart solutions: Costs and benefits. Cambridge: Cambridge University Press, 2013: 137-61.

25. Chisholm D, Moro D, Bertram M, et al. Are the "Best Buys" for Alcohol Control Still Valid? An Update on the Comparative CostEffectiveness of Alcohol Control Strategies at the Global Level. J Stud Alcohol Drugs 2018;79:514-22.

26. Caro JC, Corvalán C, Reyes M, et al. Chile's 2014 sugarsweetened beverage tax and changes in prices and purchases of sugar-sweetened beverages: an observational study in an urban environment. PLoS Med 2018;15:e1002597.

27. Watkins DA, Yamey G, Schäferhoff $M$, et al. Alma-Ata at 40 years: reflections from the Lancet Commission on investing in health. Lancet 2018;392:1434-60.

28. Álvarez-Sánchez $\mathrm{C}$, Contento I, Jiménez-Aguilar A, et al. Does the Mexican sugar-sweetened beverage Tax have a signaling effect? ENSANUT 2016. PLoS One 2018;13:e0199337.

29. Oosterhoff M, Joore M, Ferreira I. The effects of school-based lifestyle interventions on body mass index and blood pressure: a multivariate multilevel meta-analysis of randomized controlled trials. Obes Rev 2016;17:1131-53.

30. Verguet S, Gauvreau CL, Mishra S, et al. The consequences of tobacco tax on household health and finances in rich and poor smokers in China: an extended cost-effectiveness analysis. Lancet Glob Health 2015;3:e206-16.

31. Nikaj S, Chaloupka FJ. The effect of prices on cigarette use among Youths in the global youth tobacco survey. Nicotine Tob Res 2014;16(Suppl 1):S16-S23.

32. Shang C, Huang J, Cheng K-W, et al. Global evidence on the association between Pos advertising bans and youth smoking participation. Int J Environ Res Public Health 2016;13:E306.

33. Saffer H, Dave D. Alcohol advertising and alcohol consumption by adolescents. Health Econ 2006;15:617-37.

34. Saffer H, Dave D. Alcohol advertising and alcohol consumption by adolescents. NBER Working paper 9679. Cambridge: National Bureau of Economic Research, 2003.

35. WHO. Fiscal policies for diet and prevention of noncommunicable diseases: technical Meeting report. 2016. Geneva, Switzerland: World Health Organization, 2015.

36. India State-Level Disease Burden Initiative Collaborators. Nations within a nation: variations in epidemiological transition across the states of India, 1990-2016 in the global burden of Disease Study. Lancet 2017;390:2437-60.

37. Sivagurunathan C, Umadevi R, Rama R, et al. Adolescent health: present status and its related programmes in India. Are we in the right direction? J Clin Diagn Res 2015;9:LE01-6.

38. Brown HS, Stigler M, Perry C, et al. The cost-effectiveness of a school-based smoking prevention program in India. Health Promot Int 2013;28:178-86.

39. Kaneda T, Mbau-Simba L, Osewe N. Promoting healthy behaviors among youth to tackle Kenya's growing noncommunicable diseases epidemic. Washington D.C: Population Reference Bureau, 2017. 